\title{
The Use of English Adjectival Affixes by Iraqi EFL Learners:
}

\author{
An Error Analysis \\ Sabeeha Hamza Dehham ${ }^{1}$ \\ ${ }^{1}$ College of Basic Education, University of Babylon, Babil, Iraq \\ Correspondence: Sabeeha Hamza Dehham, College of BasicEducation, University of Babylon, Babil, Iraq
}

Received: February 23, 2016

Accepted: March 6, 2016

Online Published: March 10, 2016

doi:10.5430/elr.v5n1p14

URL: http://dx.doi.org/10.5430/elr.v5n1p14

\begin{abstract}
This study is mainly concerned with English adjectival affixes as one of the common and essential processes in the English derivation on the one hand, and as a problematic area for English foreign language learners on the other hand. This study hypothesizes that:

(1) Iraqi EFL university learners do not often have a full mastery of adjectival affixes and their different types. (2) Such learners encounter difficulties in using these affixes due to various factors. (3) The learners' performance at the recognition level is expected to be better than their performance at the production one.

These hypotheses have been verified through adopting a diagnostic test of four questions. The test has been applied to a sample of 150 Iraqi EFL university learners at their fourth year from Departments of English, Colleges of Education, Universities of Babylon, Baghdad, and Al-Qadissiya during the academic year 2014 - 2015. Then the subjects' responses have been collected and analyzed to draw the findings of this study.
\end{abstract}

Keywords: EFL Learner, Adjectival, Affix, Error Analysis

\section{Introduction}

\subsection{Introduce the Problem}

Learning a foreign language is a difficult task for all learners who find difficulties in how to select the word whose symbols accurately represent the concept which they have in their minds, and how to select the proper word to fit a concept. Rowley (1971: 165) asserts that acquiring vocabulary is one of the most tedious learning tasks confronting the language learners. The tasks are difficult not only because of the large number of words that must be mastered, but also because so little attention has been given to the problem of making the learner's job easier.

The present study is concerned with adjectival affixes. Adjectives are words that modify nouns or pronouns. They fall into a broad class of words called modifiers. A modifier is any word that acts to describe or qualify another word in such a way that it changes the meaning of other words (Strumpf and Douglas, 1999: 97). Describing and qualifying nouns and pronouns are the primary functions of Adjs:

(1)a- They bought a beautiful house.

b- The building looks nice.

(Fuchs et al., 1988:151)

c- The procedure proved unreliable.

(Anson \&Schwegler, 1998:297)

d- We found her tiresome.

(Strumpf and Douglas, 1999: 97)

In principle, Adjectives may be formed from all other word classes, as a result of their noun modifying function. They can be derived from nouns, verbs and Adjectives, i.e., from verb: love/lovable; from noun: center/central. Adjectives forming morphemes are called prefixes, suffixes, and zero (Leipzig, 1987: 204).

Iraqi EFL learners may not have a full mastery of distinguishing adjectival affixes owing to the difficulties they encounter in using them. These difficulties may be due to the nature of the English system which is different from Arabic system at the levels of phonology, morphology, and syntax. For example, in English, the noun agentive and the comparative adjective are realized through external change, whereas in Arabic the equivalent forms are realized through internal and external changes. Compare: 
EnglishArabic

Adj.small - smaller $\quad$ \{sagiir $\}$ \{asgar $\} \quad$ (Al-Jumaili, 1987: 3)

The present study aims at:

1- Measuring the Iraqi EFL university learners' performance in recognizing and producing adjectival affixes.

2-Analyzing and evaluating the students' errors according to the results obtained from the test and coming up with recommendations.

3- Knowing the reasons behind the students' errors.

\subsection{Hypotheses}

In order to achieve the aims of the present study, the following hypotheses have been postulated:

1- Iraqi EFL university learners do not often have a full mastery of adjectival affixes and their different types.

2- Such learners encounter difficulties in using these affixes due to various factors.The first factor includes the difficulties which are inherent in the nature of the English derivational system at the levels of phonology, morphology, and syntax. The second factor relates to the processes of interference (or transfer) and overgeneralization.

3- The learners' performance at the recognition level is expected to be better than their performance at the production level.

\subsection{Procedures}

The following procedures will be used in this study:

1- Selecting a sample of Iraqi university learners as subjects for administrating a test to point out the difficulties that they encounter in using adjectival affixes.

2- Carrying out a statistical study of the testees to locate the troublesome spots, and decide their difficulty rate.

3. Analyzing and classifying the errors committed by the Iraqi EFL university learners.

\subsection{Limits of the Study}

This study is confined to:

1-University learners at their fourth year in the Departments of English, Colleges of Education, Universities of AlQadissiya ,Babylon, and Baghdad during the academic year (2014-2015). The fourth year students have been chosen to apply the test, as they are supposedly the most advanced and qualified learners in the area of affixes at the university level.

2. Suffixes and prefixes.Prefixation and suffixation have been chosen from among the various processes of wordformation in English on the basis of the importance of these subjects as compared with other processes of word formation.

\section{Adjectival Affixes}

Affixation is the process of attaching an affix to a base as the derivation of the word 'happiness' from 'happy' (Trask, 1993:11).

Fon (2003:22) defines affixation as "a process of forming words by adding affixes to morphemes". Affixes, on the other hand, are types of bound morphemes. Their function is to modify the meaning of the root. They are divided into three types, depending on their position with reference to the root: prefixes (attached before another morpheme), suffixes (attached after another morpheme), and infixes (inserted within the morphemes) (Yule, 1999:69), (Crystal, 2004:128), (Canapero\& Elena, 2005: 2), (Schütz, 2005:5), and (Wikipedia, 2005:3).

Prefixes are bound morphemes that occur before a base. They usually do not occur alone as free forms or directly before suffixes. Two affixes may occur in sequence as in (un- and im-) as in "unimpressed" .The word 'prefix' comes from Latin "prefixum" (something fixed in front) (Eastwood, 2000:369). In word- formation, a prefix is productive when it contributes to the meaning of a word (the 'un -' in unhappyhaving the meaning of "not") can be added freely to other examples or comparable words as in: unable, unkind...etc. Prefixes are divided into two types: class- maintaining and class- changing.

The term 'suffixation' refers to the process of adding suffixes that are bound morphemes which occur after a base. Hartmann and Stork (1976:225) define a suffix as "an affix added to the end of a word". For Thomson and Martinent 
(1980: 348) a suffix is "a group of letters added to the end of a word". The suffix may be inflectional such as case ending in Latin or the plural ending '-s' in boys, or derivational such as '-ness' in kindness, happiness.

In English, the adjective is a part of speech which can be thought of as a "describing word". Crystal (2004:197) defines Adj as "a word used to qualify a noun, to restrict the application of a noun by adding something to its meaning". Thus, Adjs modify other words. They can be used to add, qualify, focus, limit or extend the meaning of words they modify. For example:

(5) a-He had a red car. (theAdjred adds to the meaning of the $\mathrm{N} \underline{\text { car}}$ ).

b-There were very small crowd. (theAdjsmall focuses the meaning of the noun crowd). (Anson \&Schwegler, 1998:277)

Adjectivals, like nominals, occupy a certain characteristic in sentence positions. The main one is that between the determiner and the noun, e.g.,

That joyful freshman

(Stageberg, 1981:212)

In this noun phrase joyful is an Adj by form - the head noun plus the derivational suffix - ful - and an adjectival by position (ibid.: 208).

Inlinguistics, adjectival affixes are bound morphemes which, in contrast with free morphemes, cannot normally stand alone, but are typically attached to other forms (Urdogan, 1982:38). According to Wikipedia (2005:3), adjectival affixes are morphemes which are attached to other morphemes to form adjectives.

In principle, the Adj may be formed from all word classes, mainly as a result of their noun -modifying function. Adj-forming morphemes are prefixes, suffixes, and zero. The frequent means of Adjs-formation are from other word-classes or Adj (Leipzig, 1987:204).

Leech (1989:16) indicates that the learner can recognize many Adjs by their endings. He classifies these endings into two groups: (1) more common endings such as -al, -ent, -ous, -ic, -ive, -able (-ible), -ful, -an, -ing, -less, -ar, and (2) less common endings like, -y, -ed, -en, -like, -ory.

There are different classifications for the adjectival suffixes.

\subsection{Suffixes Forming Adjs}

Suffixes forming Adjs can be classified into three groups:

1- Suffixes used to derive Adjs from Ns.

2- Suffixes used to derive Adjs from Vs.

3- Suffixes used to derive Adjs from Adjs.

2.1.1 Suffixes Used to Derive Adjs from Ns

There are different suffixes used to derive Adjs from Ns.They can be illustrated as follows: -al,-less,-ful.-ous,-able,-ish,-y,-an,-ary.

-al

-al [ $\rightarrow$ Adj] concerning of; having the character of ; pertaining to or related to what the $\mathrm{N}$ means:

"environmental" problems (= are related to the environment)

an "accidental" change (=happens by accident ) (Sinclair, 2002:6)

A number of -al words are used, even in Latin, as noun as well as Adjs, and many are used in this way in English too: An example is principal in the following sentences:

(6) a-The principal reason is not clear. (Adj)

b-The principal of the school comes early. (N)

-less

- less $[\mathrm{N} \rightarrow \mathrm{Adj}]$ without; free form; or beyond the range of:

(7) a-Most people think of measles as harmless.

b-The injustice of it all left me speechless.

Some Adjs formed in this way are sometimes used in a non-literal way: 
(8) a-You're brainless, you can't even count .

b-He was a spineless coward .

(Sinclair, 2002:98)

Adjs formed with this suffix can be used to form -ly adverbs:

(9) hopelessly endlessly carelessly

Sometimes Adjs formed with this suffix are called negative Adjs:

(10) a-They were completely hopeless.

b-That was very thoughtless of you. (Collins Cobuild English Grammar, 1999:214)

-ful

-ful [N $\rightarrow$ Adj]: full of; or having this quality or characteristics:

(11) a-He is a charming boy with the most beautiful hair.

b-It is a large and flavourful fungus

-ous

-ous [N $\rightarrow$ Adj] : full of , causing or having the nature (quality ) of, or pertaining to :

dangerous advantageous nervous (Smith,1966:43)

famous ambiguous obvious religious (Graver,1972:242)

There are a number of variations of the spelling of -ous. The most common ones are '-eous', '-ious' and '-uous'. For example:

-able (also -ible, -uble, -ble) [N $\rightarrow$ Adj], showing qualities of, able to, or suitable to be:

knowledgeable (well-informed, or having knowledge)

marriageable ("of a young person" fit for marriage)(Adams, 1973:12)

treasonable (quality of treason) (Schuster, 1965: 117)

-ish [N $\rightarrow$ Adj], Adj in -ishhas different meanings:

1-(with names of countries and areas) it means, "belonging to":

Swedish Turkish Danish Jewish Polish (Schuster, 1965:119)

2-(with concrete Ns) it means, "having the character of":

foolish selfish slavish wolfish (Warriner et al., 1977:161)

3- (with ages and times) it means, "about", or "approximately":

4-(with personal nouns) it means "proper to the nature of", "resembling", or "in the manner of":

boyish girlish childish womanish mannish

(Longman Dictionary of Contemporary English, 1978:591)

The derivative usually has an unfavorable meaning:

-y [N $\rightarrow$ Adj ], has two different meanings:

(1) Full of; covered with; or tending to:

dirty hairy sleepy rainy dusty

(Jesperson, 1965:76)

sunny muddy foggy smoky cloudy

(Frank ,1972:128)

(2) like ; like that of; or fond of :

a cold wintery day, a horsy person. ～(Longman Dictionary of Contemporary English, 1978:1275)

-an (-ian)

-an (-ian) [N $\rightarrow$ Adj], has three meanings:

1-(a person who or thing that is) of belonging to:

American Christian Brazilian Cuban (Long, 1961:402)

2- like or like of: 
(13) Mozarteanmusic; Shakespearean novel

3- (a person who is) belonging to the period of: Elizabethan, Georgian, Freudian, Mohammedan( Zandvoort, 1975:311); (Quirk et al., 1985 1552)

Words with this suffix use as Adjs as well as Ns:

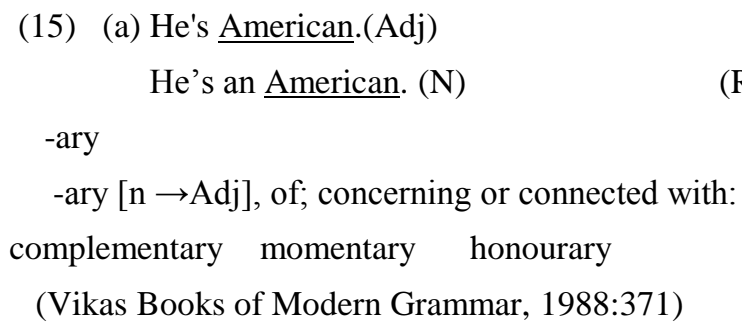

here are a number of Adjs ending in -ary that are formed from stems which are not current words in English. Thus, the suffix -ary appears almost exclusively in words with Latin roots:

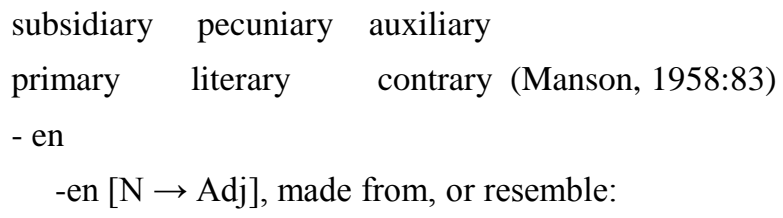

For more details the following sentences have Adjs with this suffix:

(17) a - People here wear woolen clothing even on hot days.

- ese

-ese [N $\rightarrow$ Adj] : ( the people, places, languages which are) belonging to (a country):

Nepalese Portuguese Maltese

Words with -ese are used as Adjs as well as Ns. Compare:

(18) a- A Japanese has joined our class. (N)

b-He sang a Japanese song.(Adj)

(Oxford Advanced Learner's Dictionary, 1974:1026)

-esque combines with names of famous people, for example writers, composers, or painters, in order to form Adjs:

HaydnesqueTarzanesque

(Smith, 1966:47)

ChaplinesqueBeethovenesque (Jesperson, 1961:326)

-ic(al )

$-\mathrm{ic}(\mathrm{al})[\mathrm{n} \rightarrow \mathrm{Adj}]:(1)$ connected or involving with:

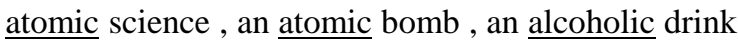

(,Longman Dictionary of Contemporary English 1978:554)

(2) resembling ( or like); having the quality of, or characteristic of:

(19)heroic $=$ hero + -ic means characteristic of (or like a hero).

poetic $=$ poet + -ic means characteristic of (or like )poets or poetry.

Byronic $=$ Byron +- ic means like the poet Byron .

(Canney et al., 2002:4; Gries, 2005:7)

- like

-like [N $\rightarrow$ Adj], similar to; having the characteristics of; or in the manner of:

(20)birdlike flowerlike dreamlike honeylike (Quirk et al., 1985:1002)

clocklike prison-like pillar-like

(Schuster ,1965:119)

$-1 y$ 
-ly [N $\rightarrow$ Adj] (1)like in the manner ( nature or appearance); similar to : queenly motherly orderly princely deadly

(2) happening at regular periods of, or recurring or repeated at an interval:

hourly yearly monthly (Kelley, 1998:2)

Generally when a word ends in -ly in English it is an adverb. However, there are few words ending in -ly that are Adjs, and these-lyAdjs can cause confusion to the learners (Phillips, 1996:204).

In this respect, Gethin (1983:125) states that some -lyAdjs (relating to the manner/ frequency) have the same form as Adjs.Compare:

(21) a-I receive quarterly bills.(Adj)

b- I pay the bills quarterly. (Adv) (Eckersley \& Eckersley, 1977:66)

-some [N $\rightarrow$ Adj]: in the quality or manner of; likely to; productive of:

troublesome worrisome bothersome (Zandvoort,1975:318)

-worthy $[\mathrm{N} \rightarrow \mathrm{Adj}]$ : is used to describe people or thing that deserve or merit whatever the nouns refer to:

creditworthy praiseworthy respectworthy(Oxford Advanced Learner's Dictionary ,1974: 995)

The following sentences show Adjs with this meaning:

(23) a- She is well-balanced, hard working and trustworthy.

b-I can hardly remember one right decision, one praiseworthyaction.

(Sinclair, 2002:186)

-ular [N $\rightarrow$ Adj]: related to; pertaining to; or characterized by:

(25) angular globular rectangular vehicular tubular

(Longman Dictionary of Contemporary English,1978:42)

-ular also occurs in Ns that refer to shapes in order to form Adjs that describe things with that shapes:

(26) a-This is a large circular pool of very clear water.

-ate $[\mathrm{N} \rightarrow$ Adj] full of; showing status or function:

passionate affectionate confederate Latinate (Concise Oxford Dictionary, 1999:24)

-based [N $\rightarrow$ Adj]: relied on:

money-based lead-based oil-based water-based (CONCISE OXFORD DICTIONARY, 1999:111)

Adjs derived in this way express the idea that the thing referred to by the original noun is the most important part or feature of something:

acid-based export-based cash-based fuel-based (Sinclair, 2002:19)

-minded

-minded [ $\mathrm{N} \rightarrow$ Adj]: interested in, or concerned with:

economy-minded care-minded reform-minded nuclear-minded

-size(-sized) [N $\rightarrow$ Adj], Adjs formed in this way are used to describe one thing as being approximately the same size as another.i.e

mansion-size apple-sized cat-sized medium-sized (Sinclair, 2002:155)

-ward [N $\rightarrow$ Adj]: moving on, or directed toward the front:

(30) eastward skyward backward upward

-th [N $\rightarrow$ Adj], denoting grade or rank, '-th' combines with most cardinal number to form the corresponding ordinals and, with phonetic changes: fourth thirteenth twenty-sixth hundredth

\subsubsection{Suffixes Used to DeriveAdjs from Vs}

Adjs can be derived from Vs with the following suffixes: -able,-ent,-ive,

-able (-ible) 
-able (also -ible and -ble) [V $\rightarrow$ Adj]: able or needing to be; fit for; worthy to, or likely to suffer the stated action: bearable payable eatable acceptable desirable remarkable (Schuster,1965:117)

preferable reasonable lovable (Aarts\& Aarts:1982:28)

-ent(-ant) [V $\rightarrow$ Adj]:kind of agent,indication; characterized by:

dependent insistent correspondent (Jesperson, 1961:366)

important respondent persistent (TEFL Test Practice, 2004:25

Adjs formed in this way are used to describe or refer to a person or thing that performs the action or that experiences the process described by the original verb. For example:

-ive(- ative) [V $\rightarrow$ Adj]: having the quality(nature, character)of ;or having tendency to:

(31) manipulate $\rightarrow$ manipulative

speculate $\rightarrow$ speculative

talk $\rightarrow$ talkative

determine $\rightarrow$ determinative

(Kelley: 1998:3)

-ory [V $\rightarrow$ Adj]: with the purpose or effect of:

preparatory inhibitory

Often there is a change in sound and spelling in the verb part:

inflame + -ory $\rightarrow$ inflammatory

satisfy + -ory $\rightarrow$ satisfactory

introduce + -ory $\rightarrow$ introductory $\quad$ (Warriner et al., 1977:160)

\subsubsection{Participles as Adjs}

Participles are parts of the verb which do the work of Adjs.The most two important of participles are the present and the past participle:

\section{A. Present Participles as Adjs}

-ing [V $\rightarrow$ Adj]: activity; having the quality of, or characterized by:

(33) a- The experience was thrilling.

(Frank: 1972:130)

b- I heard some surprising news.

(Azar, 1999:297)

The English suff -ing has several uses that are arguably on the borderline between inflection and derivation. It sometimes causes confusion to the learners since they may recognize it as an inflectional suffix, gerunds, or as Adjs. Compare:

(34) a- The boy is standing in the corner.(V)

The boy standing in the corner was naughty. (Adj) (Phillips, 1996:103)

b-He enjoys walking. (Gerund $\mathrm{N}$ )

\section{B. Past Participles as Adjs}

-ed $[\mathrm{V} \rightarrow$ Adj] ,having the characteristic or (quality )of:

(35) a-She was a devoted mother.

b-The apples, washed and polished, are ready for theparty. (Sadlier, 2000:153)

c-The woman looks disgusted. $\quad$ (Fuchs et al., 1988:159)

A past participle often ends in -ed, but there are also many irregular past participles. They are also used as Adjs:

(36) a-There are a lot of broken bottles on the road. (Adj)

(Eckersley \& Eckersley, 1970:68)

b-They found the lost articles.

c-Was it a broken bone, a torn ligament, or what? (Sinclair, 2002; 78) 
Vs in -ing can be easily confused since the learners may distinguish them as the simple past, the past participle, or as an Adj.Compare:

(37) a-She painted this picture. (Simple past tense )

She has painted this picture. (Past perfect tense )

The picture painted by Karen is now in a museum. (Adj) (Phillips, 1996:105)

\subsubsection{Other Suffixes Used to derive Adjs from Vs}

-less [V $\rightarrow$ Adj]: without; missing; free from; or not to be -ed:

countless dauntless tameless (poetic) (Zandvoort, 1975:317)

2.1.3 Suffixes Used to derive Adjs from Adjs

Adj is also derived from other Adjs with the following suffixes:

-ish [Adj $\rightarrow$ Adj]: to some degree; somewhat; rather; or having a small amount of the characteristic or quality described by the original Adj:

longish smallish biggish bluish greenish (Zandvoort, 1975:316)

Reddish latish tallish poorish youngish

(Longman Dictionary of Contemporary English, 1978:591)

-fold [Adj $\rightarrow$ Adj]: multiplied by; of (so many) parts, combines with cardinal numbers. The following sentences have Adjs with this suffix:

(38)a-My interests were twofold, the first to make money, the second to sell the public reliable goods.

b-Criticisms of the old system were threefold.

c-The aims of the new organization are eightfold.

-ly [Adj $\rightarrow$ Adj] , having the quality or characteristic of :

(39)kind $\rightarrow$ kindly $\quad$ low $\rightarrow$ lowly

clean $\rightarrow$ cleanly $\quad$ bad $\rightarrow$ badly $\quad$ sick $\rightarrow$ sickly

The following sentences have Adjs with -ly:

(40) a-They are bright,alert, and lively.

b-The nurses looks kindly

-y [Adj $\rightarrow$ Adj]: marked by, or having the characteristic of :

chill $+-\mathrm{y} \rightarrow$ chilly $\quad$ yellow $+-\mathrm{y} \rightarrow$ yellowy

green $+-\mathrm{y} \rightarrow$ greeny $\quad$ pink $+-\mathrm{y} \rightarrow$ pinky $\quad$ (Zandvoort, 1975:319)

\subsubsection{Comparative and Superlative Suffixes:-er,-est}

-er and -est combine with qualitative Adjs:

(1)-er [Adj $\rightarrow$ Adj] comparative:

(41)newer higher fuller hotter

(42) Andrea was two years older than me. (Fuchs et al., 1988: 160-169)

(2) - est [Adj $\rightarrow$ Adj] superlative:

darkest softest coldest largest

Superlative Adjs are used to show which one of many is in some way the most outstanding:

(43) a-Maharajah was the tallest man she knew. (Sinclair, 2002:53)

here? (Swan \& Walter, 1990:123)

\subsection{Prefixes Forming Adjs}

The Frequent means of Adjs - formation are from other word-classes or Adjs by adding prefixes at the beginning of the word. There are different classifications for prefixes, but the most common one is by Quirk et al. (1989:431-5), Crystal 
(2004:128), and Canapero\& Elena (2005:1-5), whereby they classify prefixes forming Adjs into different groups. They classify them semantically as follows:

\subsubsection{Negative and Reversative Prefixes}

Negative prefixes are used to modify the meanings of the stems. They express a neutral meaning. (Zandvoort, 1975:297ff)

Reversative prefixes, on the other hand, give the opposite meaning of the words or Adjs. They express the reversal of being. These two kinds of prefixes can be illustrated as follows:

a- [Adj $\rightarrow$ Adj], not, without, lack of, or lacking in:

political $\rightarrow$ apolitical moral $\rightarrow$ amoral

typical $\rightarrow$ atypicalvaluativel $\rightarrow$ avalua

un- [Adj $\rightarrow$ Adj ], not, or deprive of :

unartistic unable unhappy

un- is also added to participles to form Adjs that describe the idea that something has not happened or not true :

unbeatenuncivilized undemanding undisturbed unchanging(Schütz, 2005:12)

non- [Adj (or n) $\rightarrow$ Adj ],(usually written with a hyphen) not , or not have the qualities or characteristics referred to:

non-committal non-existente non-flammable

non-active non-political non-academic (Leipzig,1987:204)

in- (il-,im-,ir- )

in- Adj (or Ns related to Adjs) $\rightarrow$ Adj], not:

incorrect indirect inaccurate inflexible (Radford,1998:33)

The prefix in-has a number of forms depending on the initial segment of the base:

The variant form il- is used when the base begins with the letter 'i' as in:

illegal illogical

$\operatorname{dis}-[\operatorname{Adj}(\mathrm{N}) \rightarrow \operatorname{Adj}]$, the opposite of ; not:

disobedient discouraged (Bauer, 1983:220)

disinterested discourteous (Schütz, 2005:12)

2.2.2 Pejorative Prefixes

Pejorative prefixes refer to false or imitation. They describe things as 'bad', or 'not genuine'. They can be classified as follows:

mal- [Adj (or participles) $\rightarrow$ Adj],bad ; badly ; ill :

malodorous malformed

(Quirk et al.,1989:432)

malnourished maltreated

(Zandvoort,1975:296)

The following sentence has Adj with this prefix:

(44) The child is thoroughly maladjusted.

(Sinclair, 2002:104)

Pseudo- [Adj (n) $\rightarrow$ Adj], false; imitation; not genuine:

pseudo-religious, pseudo-scientific,pseudo-intellectual, pseudo-democratic

Pseudo- is often used to show disapproval .For example, if we describe someone as a 'pseudo-friend', we think that although he appears to be friendly he is not genuinely our friend. The following examples show this prefix:

(44) a-..... a pretty, pseudo-rustic bistro.

b-He undid his coat and slung it over the back of a pseudo-oak settee.

\subsubsection{Prefixes of Degree and Size}

These prefixes are used to refer to the degree of size, quality, or quantity, of things that described by the Adjs:

Super- $[\mathrm{Adj} \rightarrow \operatorname{Adj}]$, (usually written with a hyphen), of great size or quality, more than: 
super-intelligent super-conscious ( Schütz, 2005:12)

super-heavy super-sensitive (Concise Oxford Dictionary,199:391)

The following sentences show Adjs with this prefix:

(43) a-I would choose this plant for its superabundant flowers and fruits.

b-Hemoglobin is super-efficient at the task of carrying oxygen.

sub- [ Adj (sometimes $\mathrm{n}$ ) $\rightarrow$ Adj], smaller; or less powerful

subfertile subhuman substandard sub-freezing subcentral

over- [Adj(or participles) $\rightarrow$ Adj] ,too much ,or excessive:

overconfident overdressed overloaded

( Schütz, 2005:12)

The following sentences have Adjs with 'over-' with this meaning:

(46) a-Every ledge of the cliff is overgrown with vegetation.

b-He was over-anxious to keep an appointment.

hyper- [Adj $\rightarrow$ Adj],to a large, or extreme degree:

hyperactive hypercritical hypersensitive (Schütz, 2005:15)

The following examples show Adjs with this prefix:

(47) a-The man became hypersensitive to the sights movements around him.

b-He was a hyper-cautious commander who never took risks

ultra-[Adj $\rightarrow$ Adj], extreme; to a large degree, or excessively:

ultra-conservative ultra-fashionable

(Zandvoort,1975:297)

2.2.4 Prefixes of Orientation and Attitude

These prefixes express the opinions, or attitudes towards something or someone that are described by the Adjs:

counter- $[\operatorname{Adj}($ or $n) \rightarrow$ Adj], against, in opposition to:

counterattractive counterintuitive counteractive (Leipzig,1987:204)

counter-revolution counterproductive counterreactionary (Bauer, 2004:220)

$\operatorname{anti-}[\operatorname{Adj}($ or $n) \rightarrow \operatorname{Adj}]$, against ; rival, or enemy of :

antichrist anti-war anti-catholic (Quirk et al., 1989:987)

anti-democratic anti-Marxist anti-capitalist

The following examples include Adjs with this prefix:

(48) a-She had become involved, as a student, in anti-racist movements.

b-The white group ran the anti-census campaign in 1985. (Sinclair, 2002:12)

pro- [Adj(or $n) \rightarrow$ Adj],for; in the side of; on behalf of ,or in support of:

pro-democracy pro- Western ( Leipzig, 1987:204)

pro communist pro-American ( Schütz, 2005:15)

2.2.5 Locative Prefixes

They refer to places or positions. They can be classified as follows:

super-[Adj $\rightarrow$ Adj], beyond:

superhuman supernatural super-national

The following examples have Adjs with this prefix:

(49) Pep pills produce supernormal alertness.

inter-[ $\operatorname{Adj}(\mathrm{N}) \rightarrow \operatorname{Adj}]$,between; among:

international interlanguage inter-family interpersonal 
The following examples have Adjs with inter-:

(50) a-... inter-city travel. (Longman Dictionary of Contemporary English, 1978:583)

trans-[ $\operatorname{Adj}(\mathrm{N}) \rightarrow \operatorname{Adj}]$,across; beyond, or to other side of:

trans-continental transatlantic trans-sonic

(Crystal,2004:28)

transactional transcendental

(Concise Oxford Dictionary, 1999:1521)

2.2.6 Prefixes of Time and Order

pre-[Adj(or N and sometimes participles) $\rightarrow$ Adj],before, or beforehand:

pre-school pre-industrial pre-arranged (Oxford Advanced Learner's Dictionary,1974:655)

The following examples have Adjs with this prefix:

(51) a-The squad will go Shaw Hill for pre-match training.

b-He found himself opposing Chamberlain in pre-war years.

post-[Adj(or N) $\rightarrow$ Adj], after:

post-classical post-election post-war (Schütz, 2005:17)

The following sentences have Adjs with this prefix:

(52) a-We live in a post-religious era.

\subsubsection{Prefixes of Number}

These prefixes show the number or the amount of something:

mono-[ $\operatorname{Adj}($ or $N) \rightarrow \operatorname{Adj}]$, alone, or having only one:

monosyllabic monolingual monologue

(Schütz, 2005:17)

bi- [ $\operatorname{Adj}(\operatorname{or} N) \rightarrow \operatorname{Adj}]$, two:

biennial event (happens every two years)

biweekly magazine (appears every two weeks)

(Zandvoort, 1975:293)

$\operatorname{di}-[\operatorname{Adj}($ or N) $\rightarrow$ Adj], two; twice, or double:

dioxide divalent dichotomous dichromatic

(CONCISE OXFORD DICTIONARY,1999:394)

The prefix di- is variant spelling of dis- shortened before (l, $\mathrm{m}, \mathrm{n}, \mathrm{r}, \mathrm{s})$ followed by consonant and (v); it is also often shortened before (g), and sometimes before (j). Thus, the idea of two (di- and dis-) should be tested. If it seems to be fit the sentence, the prefix must be (di-) meaning "two".

If it does not seem to fit the sentence, the prefix may be (dis-) meaning "a way", or not. For example:

(53) a-John could sometimes understand polysyllabic words better than disyllabic ones (di- means "two").

$\operatorname{tri}-[\operatorname{Adj}($ or N) $\rightarrow$ Adj ],three:

tri-clinic $\rightarrow$ \{denoting a crystal system with three equal oblique axes\}

tri-coloured $\rightarrow$ \{denoting something with three coloures

multi- [ $\operatorname{Adj}($ or N) $\rightarrow \operatorname{Adj}]$, many, or :

multi-legged multi-purpose multi-dimensional multi-talented (Sinclair, 2002:118)

poly-[Adj $\rightarrow$ Adj], many :

polytechnic polysyllabic polygraphic (Concise Oxford Dictionary,1999:1108)

semi-[Adj (N ,or participles) $\rightarrow$ Adj ], half, or partly:

semi-civilized semi-detached (Zandvoort,1975:296)

Adjs formed in this way refer to something that almost happens or is partly true:

(54) a-The semi-liquid clay is then called 'slip' . 


\subsubsection{Miscellaneous and Neo-classicalPrefixes}

auto-[N $\rightarrow$ Adj],self, without help, or independent of others :

automatic autobiographic autographic autocratic

neo-[Adj(or $\mathrm{n}) \rightarrow$ Adj ],new, revived:

neo-Freudian neo-realism neo-conservative

(Schütz, 2005:17)

pan-[Adj (or n) $\rightarrow$ Adj ], world-wide; all; involved with(used mainly with reference to world-wide or continent-wide activities ):

pan-African pan-Arab pan-chromatic (Concise Oxford Dictionary, 1999:1029)

extra- [Adj $\rightarrow$ Adj ],outside, or beyond:

(55) extraordinary extra-curricular extralinguistic

(Canapero\& Elena, 2005:1)

The following sentences contain Adjs with this prefix:

(56) a-The students benefit greatly from involvement in extra-curricular activities.

b-Before the nineteenth century, the Extra-EuropeanWorldsupplied Europe with luxuries.

\subsubsection{Conversion Prefixes}

The following prefixes change the bases into Adjs:

1. (a-) may be prefixed to the stem of monosyllabic intransitive Vs, and of disyllabic intransitive Vs ending in unstressed -er or -le ,to form predicative Adjs denoting a state:

drift $\rightarrow$ adrift $\quad$ sleep $\rightarrow$ asleep

flicker $\rightarrow$ aflickerquirer $\rightarrow$ aquirer $\quad$ (Jesperson, 1961: 5-7)

2. (be)- is added to Adjs (participial Adjs) which describe something as being a particular state or going into that state: loved $\rightarrow$ beloved $\quad$ calmed $\rightarrow$ becalmed

\section{Results of the Subject's Responses}

\subsection{Subjects' Performance of Adjectival Affixes in Question One}

The First question is constructed to measure the subjects' performance at the recognition level:

Table 1. Frequency and Percentage of the Subjects' Performance at the Recognition Level in Question (1)

\begin{tabular}{|c|c|c|c|c|c|c|c|c|c|}
\hline $\begin{array}{l}\text { No. of } \\
\text { Item }\end{array}$ & $\begin{array}{l}\text { No. of } \\
\text { CRs }\end{array}$ & $\%$ & $\begin{array}{l}\text { No. of } \\
\text { IRs }\end{array}$ & $\%$ & $\begin{array}{l}\text { No. of } \\
\text { Item }\end{array}$ & $\begin{array}{l}\text { No. of } \\
\text { CRs }\end{array}$ & $\%$ & $\begin{array}{l}\text { No. of } \\
\text { IRs }\end{array}$ & $\%$ \\
\hline 1 & 83 & 55 & 67 & 45 & 14 & 28 & 19 & 122 & 81 \\
\hline 2 & 50 & 33 & 100 & 67 & 15 & 62 & 41 & 88 & 59 \\
\hline 3 & 55 & .37 & 95 & 63 & 16 & 84 & 56 & 66 & 44 \\
\hline 4 & 87 & 58 & 63 & 42 & 17 & 94 & 63 & 56 & 37 \\
\hline 5 & 60 & 40 & 90 & 60 & 18 & 74 & 49 & 76 & 51 \\
\hline 6 & 103 & 69 & 47 & 31 & 19 & 56 & 37 & 94 & 63 \\
\hline 7 & 78 & 52 & 72 & 48 & 20 & 94 & 63 & 56 & 37 \\
\hline 8 & 81 & 54 & 69 & 46 & 21 & 96 & 64 & 54 & 36 \\
\hline 9 & 80 & 53 & 70 & 47 & 22 & 73 & 49 & 77 & 51 \\
\hline 10 & 57 & 38 & 93 & 62 & 23 & 65 & 43 & 85 & 57 \\
\hline 11 & 59 & 39 & 91 & 61 & 24 & 81 & 54 & 69 & 46 \\
\hline 12 & 90 & 60 & 60 & 40 & 25 & 66 & 44 & 84 & 56 \\
\hline 13 & 51 & 34 & 99 & 66 & Total & 1807 & 48.19 & 1943 & 51.81 \\
\hline
\end{tabular}




\subsection{Subjects' Performance of Adjectival Affixes in the Second Question}

The Second question is constructed to measure the subjects' performance at the production level:

Table 2. Frequency and percentage of the Subjects' Performance atthe Production Level in Question (2)

\begin{tabular}{llllllllll}
\hline $\begin{array}{l}\text { No. of } \\
\text { Item }\end{array}$ & $\begin{array}{l}\text { No. of } \\
\text { CRs }\end{array}$ & $\mathbf{\%}$ & $\begin{array}{l}\text { No. of } \\
\text { IRs }\end{array}$ & $\mathbf{\%}$ & $\begin{array}{l}\text { No. of } \\
\text { Item }\end{array}$ & $\begin{array}{l}\text { No. of } \\
\text { CRs }\end{array}$ & \% & $\begin{array}{l}\text { No. of } \\
\text { IRs }\end{array}$ & \% \\
\hline $\mathbf{1}$ & 100 & 67 & 50 & 33 & 14 & 43 & 29 & 107 & $\mathbf{7 1}$ \\
$\mathbf{2}$ & 77 & 51 & 73 & 49 & 15 & 7 & 04 & 143 & $\mathbf{9 5}$ \\
$\mathbf{3}$ & 38 & 25 & 112 & 75 & 16 & 83 & 55 & 67 & $\mathbf{4 5}$ \\
$\mathbf{4}$ & 72 & 48 & 78 & 52 & 17 & 19 & 13 & 131 & $\mathbf{8 7}$ \\
$\mathbf{5}$ & 44 & 29 & 106 & 71 & 18 & 79 & 53 & 71 & $\mathbf{4 7}$ \\
$\mathbf{6}$ & 26 & 17 & 124 & 83 & 19 & 19 & 13 & 131 & $\mathbf{8 7}$ \\
$\mathbf{7}$ & 13 & 09 & 137 & 91 & 20 & 7 & 04 & 143 & $\mathbf{9 5}$ \\
$\mathbf{8}$ & 59 & 39 & 91 & 61 & 21 & 6 & 04 & 144 & $\mathbf{9 6}$ \\
$\mathbf{9}$ & 42 & 28 & 108 & 72 & 22 & 65 & 43 & 85 & $\mathbf{5 7}$ \\
$\mathbf{1 0}$ & 47 & 31 & 103 & 69 & 23 & 6 & 04 & 144 & $\mathbf{9 6}$ \\
$\mathbf{1 1}$ & 35 & 23 & 115 & 77 & 24 & 19 & 13 & 131 & $\mathbf{8 7}$ \\
$\mathbf{1 2}$ & 94 & 63 & 56 & 37 & 25 & 37 & 25 & 113 & $\mathbf{7 5}$ \\
\hline $\mathbf{1 3}$ & $\mathbf{8 4}$ & $\mathbf{5 6}$ & $\mathbf{6 6}$ & $\mathbf{4 4}$ & Total & $\mathbf{1 1 2 1}$ & $\mathbf{2 9 . 8 9}$ & $\mathbf{2 6 2 9}$ & $\mathbf{7 0 . 1 1}$ \\
\hline
\end{tabular}

3.2 Frequency and Percentage of the Subjects' Performance of Adjectival Affixes in the Whole Test

Table 3. Subjects' Performance at the Recognition and the ProductionLevels throughout the Whole Test

\begin{tabular}{llclc}
\hline Level & $\begin{array}{l}\text { No. of } \\
\text { CRs }\end{array}$ & \% & $\begin{array}{l}\text { No. of } \\
\text { IRs }\end{array}$ & \% \\
\hline Recognition & 1807 & 48.19 & 1943 & 51.81 \\
Production & 1121 & 29.89 & 2629 & 70.10 \\
\hline Total & $\mathbf{2 9 2 8}$ & $\mathbf{3 9 . 2 6}$ & $\mathbf{4 5 7 2}$ & $\mathbf{6 0 . 9 6}$ \\
\hline
\end{tabular}

\section{Sources of Errors}

Brown (1987:177) mentions four factors to which students' errors can be attributed. They are interlingual transfer, interalingual transfer, context of learning, and communication strategies.

\subsection{Interlingual Transfer}

Errors are due to the existence of a language system that the learner develops at a certain stage of his learning the foreign language. This language system is a mixture of elements derived from both L2 and L1, but is in no way limited to either (Ellis, 1984:69).

In English, the derivation of Adjs shows the external changes, whereas in Arabic it shows the internal and external changes. Some of interlingual errors are widespread at the production level.

The main cause of these errors is likely to be associated with the negative transfer of Arabic in the form of a translation strategy in producing words in English (Farooq 1998:11).

\subsection{Intralingual Transfer}

Intralingual errors occur within L2 itself as a result of misinterpreting its grammatical rules. They reflect the characteristics of rule learning of that language. Such errors occur at both levels: the recognition and the production. They may be attributed to four factors: overgeneralization; ignorance of rule restrictions; false concepts hypothesized; and incomplete application of rules.

"Overgeneralization" refers to the incorrect application of the previously learned material to a present foreign language context (Ellis, 1984:171).

The other source of errors is "ignorance of rule restrictions". In this case the learners apply a rule to a category which is an incorrect place that leads to error committing. The subjects may use verbal affixes or nominal affixes to derive Adj as a result of an analogical extension. 
Another source of errors is "incomplete application of rules". The learners fail to apply complex rules completely since they are complex and hard in learning and use. Instead they tend to use simple constructions to achieve effective communications.

This kind of errors can be found in items $(13,14$ and 23) in Q.2. The subjects use adjectival affixes in more than one place since it is easier for them to use this rule than the right complex one:

Item (13) *healthly healthy

Item (14) *unvisible invisible

Item $(23) *$ innormal subnormal

The last factor of intralingual transfer is "thefalse concepts hypothesis". According to Richards (1980:178), "false concepts hypothesis is a well observed phenomenon in the field of L2 learning". Due to the field of L2 learning, L2 learners are seen to adopt the wrong hypothesis or build the wrong rule about L2. This kind of errors may result from faulty comprehension of any distinction in the target language (Ellis, 1984:171). This can be seen in items (4,8 and 12) in Q.2:

Item (4) The prime minister made a *personing \{personal\} appearance at the meeting.

Item (8) He greeted them with a *cherrfy \{cheerful $\}$ grin.

Item (12) That was a very *friendful $\{$ friendly $\}$ thing to do.

\subsection{Context of Learning}

Errors ofcontext of learning refer to the negative influence of elements of learning situation, such as the classroom, the lecture, and the curriculum. These kinds of errors are also called "induced errors", which refer to the errors caused by the way in which language items have been taught. The misleading explanations by the teacher, incomplete or faulty presentation of linguistic structures or elements lead students to make false concepts or hypotheses about the language (Brown, 1987: 179).

The most obvious cases which reveal the influence of the context of learning on the subjects' responses are in items $(10,17$ and 24$)$ in Q.1:

Item $(10) *$ permissionpermissible

Item (17) *love beloved

Item (24) *oiled-well well-oiled

\subsection{Communication Strategies}

Communication strategies are used by learners to overcome a communication problem caused by a lack of or inability to access L2 knowledge (Ellis, 2003: 340). Second language learners will inevitably experience moments where there is a gap between communication intent and their ability to express that intent. Some learners may just stop talking; others will try to express themselves using communication strategies (Yule, 1999:197). Corder (1973:104) states that the subjects' errors in communication strategies are due to reduction or avoidance strategies .He calls the first one as "risk-avoidance" and the second one as "risk -taking" or "resources expansion".

This type of errors takes place within the structure of the foreign language itself. It falls into four strategies:

"Avoidance" is one of these strategies. It means not saying what one wants to say, so one has the ability to solve the problem of how to express it (Yule, 1999:197).

According to this strategy the subjects may tend to give no responses or make no choices. In other words, avoidance strategy has been used and represented by the items that were left by the subjects with no responses.The influence of this strategy can be seen in items $(9,10,15$, and 17) in Q.1 , in items $(5,7$ and 21) in Q..

The second strategy is "guessing". The subjects use clues that are language or non-language based, such as knowledge of a context, world, or text structure, in order to guess the meaning, in the absence of complete knowledge of vocabulary, grammar, or other target language elements (Brown, 1987: 183). "Approximation is the third strategy. The subjects use a word for a related meaning to that intended (ibid.).

Errors of approximation can be illustrated by the following examples from items items (1, 9, and 24) in Q.2:

Item (1) Did he really see a ghost or was it only a *subjectous\{subjective\} impression.

Item (9) Don't eat those berries. They're *poisonal \{poisonous\}. 
Item (24) She asked us to her house which was very small and *intidy $\{$ untidy .

The fourth kind of communication strategy is "circumlocution". It is also called "paraphrase" (i.e., using different words similar in meaning to the original ones (Crystal, 1991:278).

Some errors of this strategy can be clarified by the following examples from Q.4, items (19 and 23):

\section{Conclusion}

In the light of the preceding survey and discussion related to the findings, aims and hypotheses of this study, the following conclusions have been drawn:

1- Iraqi EFL university learners at the fourth stage face difficulty in recognizing and producing adjectival affixes. This is indicated by their low performance in the main test as the rate of their correct responses (39.26\%) is lower significantly than that of their incorrect ones $(60.96 \%)$. This validates the first hypothesis of this study which states that Iraqi EFL university learners do not often have a full mastery of adjectival affixes and their different types.

2-The subjects' performance in the whole test has also revealed that EFL university learners encounter more difficulties in using adjectival affixes at the production level than at the recognition one.This validates the third hypothesis of this study which indicates that the learners' performance at the recognition level is expected to be better than their performance at the production level.

\section{Recommendations}

In the light of the discussion of the results of the present study, the following recommendations can be posited:

1) More emphasis should be given to the topic under investigation at all levels of education.

2) English affixes must be taught by means of communication tasks and real -life situations which providemeaning or in the form of conversation.

3) More practices and exercises should be conducted among students in English adjectival affixes so that thestudents can recognize the types of these affixes.

4) Depending on the types of the errors made by the subjects of this study, the teachers/ instructors should takethese errors into consideration and ask their students to avoid such errors.

\section{References}

Aarts, F \&Aarts, J. (1982). English Syntactic Structures. London: Prentice-Hall.

Adams, V. (1973). An Introduction to Modern English Word-Formation. London: Longman.

Advanced English Dictionary. (2001). Dalgish, M. (ed.). New York: Random House. Inc.

Al-Jumaili, S. (1987). Inflectional Suffixes in English with Reference to Teaching English in Iraqi Secondary Schools. Unpublished M. A. Thesis.College of Arts, University of Baghdad.

Anson, C. M. \& Schwegler, R. A. (1998). The Longman Handbook forWriters and Readers. London: Addison Wesley Longman.

Azar, B. S. (1999). Understanding and Using English Grammar. $3^{\text {rd }}$ ed. New Jersey: Prentice - Hall, Inc.

Bachman, L. F. (1990). Fundamental Consideration in Language Testing. New York: Oxford University Press .In Brown, J. Dean. 1990 Testing in Language Programmes. Englewood Cliffs: Prentice -Hall, In.

Bauer, L. (1983). English Word-Formation .Cambridge: CambridgeUniversity Press.

......... (2004). The function of Word-Formation and Inflection-Derivation. Victoria: University of Wellington. Internet.http:www.vuw.nz//als/staff/laurie-bauer/Bauer-Infl-Deriv-pdf

Brown, J. D. (1987). Principles of Language Learning andTeaching. $3^{\text {rd }}$ ed. New Jersey: Prentice Hall regents.

........... (1996). Testing in Language Programmes. Englewood Cliffs: Prentice - Hall, Inc.

Canapero, M \& Elena, Nalon. (2005). Grammar \& Language in Use:Prefixes.Internet.http:/claweb.cla.unipd.it/home/mcanapero/ grammar_main.htm.

Canney, J.F., Goldberg, J.P. \&D.Oc'onner, D. (2002). Suffixes to Know:From Working on Words. Washington: GallaudetUniversity. Internet.mailto: English, works@ gallaudet.edu,terry, coye.

Collins Cobuild English Grammar. (1999). London: William Collins Sons. Ltd.

Concise Oxford Dictionary. (1999). Judy, Pearsall (ed.) Oxford: Oxford University Press. 
Corder, S. P. t. (1973). Error Analysis .In Allen J.P.B. and Corder S.P.T.(2 ${ }^{\text {nd }}$ ed.) Techniques in Applied Linguistics (The EdniburghCourse in applied Linguistis: 3), London: Oxford University Press.

Crowell, T. L. (1964). Index to Modern English. New York: McGrow - Hill,Inc.

Crystal, D. (1991). A Dictionary of Linguistics and Phonetics. Oxford: Oxford University Press. (2004). The Cambridge Encyclopedia of the EnglishLanguage. Cambridge: Cambridge University Press.

Eastwood, J. (2000).Oxford Guide to English Grammar. Oxford: Oxford University Press.

Eckersley, C. F \& Eckersley, J. M. (1970). A Comprehensive EnglishGrammar for foreign students. London: Longman.

Ellis, R. (1984). Understanding Second Language acquisition. Oxford: Pergamon Institute of English. (2003). A Task - based Language Learning and Teaching. Oxford: Oxford University Press.

Farooq, M.U. (1998). Contrastive and Error Analysis based Teaching Strategies. Internet.Bulletin of Aichi Women's Junior College.General Education and Interdisciplinary.

Fon, J. (2003). Morphology. The Ohio University Press.Internet. Http://www.Google .com.

Fowler, H.W. (1958). A Dictionary of Modern English Usage. Oxford: Oxford University Press.

Frank, M. (1972). Modern English. London:Prentice-Hall, Inc.

Fuchs, M. Westheimer, M. \& Bonner, M. (1988). Focus onGrammar.London: Addison-Wesley Publishing Company.

Gethin, H. (1983). Grammar in Context: Proficiency Level English. London: Collins. ELT.

Graver, B. D. (1972). Advanced English Practice. $2^{\text {nd }}$ ed. London: Oxford University Press.

Gries, S. (2005). A Corpus-Linguistic Analysis of English - ic vs - icalAdjectives. University of Southern Denmark at Sonderborg. Internet.http:// www.ercim.org /pub/ bsew.cg/d16107/DS.

Hills, D. (2005). Grammar.Internet.http: /www. ex. ac. ul/Grammar/ adjective v.htm.

House, H. C. \& Hartmann, S. E. (1950). Descriptive English Grammar.Englewood Cliffs: Prentice - Hall.

Jesperson, O. (1961). A Modern English Grammar on Historical Principles: Morphology. London: Bradord and Dickens Drayton House.

............ (1965). English Grammar. London: George Allen.

Kelley, W. (1998). Eight Derivational Suffixes in American English.University of Wisconsin at Madison fall.Internet.Ladys / urmission.com.

Leech, G. (1989). An A - Z of English Grammar and Usage.London: arson Education Limited.

Leech, G. Deuchar, M. and Hoogenrod, R. (1985). English Grammar for Today. London: Macmillan Press.

Leipzig, V. V. (1987). English Grammar: A University Handbook. Berlin: VebVerlagEnzyklopädie.

Long, R. B. (1961). The Sentence and its parts: A Grammar ofContemporary English. Chicago: The University of Chicago Press.

Longman Dictionary of Contemporary English: The up - to - date Learning Dictionary. Procter, Paul.ed. 1978. London: Longman.

Manson, S. C. (1958). Word-Building.New York: Macmillan Company. Matthews, P. H. 1974. Morphology: an Introduction to the Theory ofword - Structure. Cambridge: Cambridge University Press.

Oxford Advanced Learner's Dictionary. (1974). London: OxfordUniversity Press.

Oxford Wordpower Dictionary. (2000). Wehmeir, S. (ed.). London: OxfordUniversity Press.

Phillips, D. (1996). Longman Preparation Course for the TOEFL Test. London: Addison - Wesley Publishing Company, Inc.

Quirk, R., Greenbaum, S. \& Leech, G.\&Svartvick, J. (1985). A Comprehensive Grammar of the English Language.London: Longman.

.......... (1989). A Grammar ofContemporary English. London: Longman. 
Radford, A. (1998). Transformational Syntax: A Students Guide toChomskys extended standard Theory. Cambridge: Cambridge University Press.

Richards, J. C. (1980). A Non-Contrastive Approach to Error Analysis: Perspective on Second Language Acquisition. London: Longman.

Roberts, P. (1967). Modern Grammar. New York: Harcourt, Brace and world Inc.

Rowley, H. B. (1971). Advanced English Vocabulary.English LearningJournal, 24, 167.

Sadlier, W. H. (2000). Grammar for Writing. New York: WilliamSchuster, E .1965. Grammar, Usage, and Style. New York: McGraw-Hill, Inc.Sadlier, Inc.

Schütz, R. (2005). Word-Formation.Internet.http://www.sk.com.br/sk-inst-html\#inst.

Sinclair, J. (2002). Word-Formation: Prefixes and Suffixes. London: Collins Cobuild English Guid.

Smith, L. P. (1966). The English Language. Oxford: Oxford UniversityPress.

Stageberg, N. (1981). An Introductory to English Grammar. $4^{\text {th }}$. ed.Florida: Holt, Rinehart and Winston, Inc.

Strumpf, M \& Douglas, A. (1999). The Grammar Bible. Los Angeles:MichaelStrumpf and AurielDouglas.

Swan, M. \& Walter, C. (1990). The New Cambridge English Course.Cambridge: Cambridge University Press.

TEFL Test Practice. (2004). Cambridge: Cambridge University Press. Thakur, D. 2002. Linguistics: Simplified Morphology.Panta:BPrinter.

Thomson, A. J. \& Martinent, A. V. (1980). A Practical English Grammar.Oxford: Oxford University Press.

Trask, R. L. (1993). A Dictionary of Grammatical Terms inLinguistics. London: Routledge.

Urdogan, L. (1982). Suffixes and other Word-Final Elements ofEnglish. Detroit: Grale.

Vikas Books of Modern Grammar. (1988). New Delhi: Vikas publishingHouse PVT, LTD.

Warriner, J. E., Whitten, M. E. \& Griffith, F. (1977). English Grammar and Composition. New York: Harcourt Brace Javanovich.

Wikipedia: The Free Encyclopedia. (2005). Florida:SantPeterpersburg.Internet.http://en.wikipedia.org/wiki/affix.

Yule, G. (1996). The Study of Language. $2^{\text {nd }}$. ed. Cambridge: CambridgeUniversity Press.

Zandvoort, R .W. (1975). A Handbook of English Grammar. London: Longman.

Appendix I

The Test

Q1: Choose a word which has an adjectival affix (a suffix or a prefix) from the words between brackets to complete the sentence. (25 marks)

1-A youngster has more time to be (creation /creative)

2-It was one of the most .......... sights I have ever seen.(frightening /frighten)

3-She was now the.........cook in the house. (assistant/assistance)

4-Many people these days prefer. ............clothes. (Italy/ Italian)

5-Most of the roads were still impassable to......movements. (vehicular / vehicling,)

6-I enjoy teaching that class because the children's minds are so .......... (reception, receptive)

7-Criticisms of the old system were ........ (fold -three / three-fold)

8 -What is a shocking and..........story? (shamefully / shameful)

9-You don't have to be an ......... person to realize that there is something wrong with this society. (idealistic / idealize)

10-I understood that it was .........to ask a question. (permissible/ permission)

11-The sky was.........and light rain was falling. (becloud/cloudy)

12-The hotel was large and ...........(comfortable/comfortably) 
13-He is incredibly rich.He is certainly a. .(supermillionaire, submillionaire)

14-They were jailed for organizing, training and equipping a organization. (pre-military / para-military)

15-She had become involved, as a student, in. movements.

(anti-racist / non-racist,)

16-That sweater was. . (all-wool / wool-all)

17-He was pleased still to be in Austria and close to his wife. (love / beloved)

18-The conditions of the jails are (subhuman / post-humam)

19 -There is a magazine for teenage girls. (bi-weekly, tri-weekly)

20-The hard-working carpenter had never done a thing in his life. (dishonest / non- honest)

21-Many students benefit greatly from being involved in.... activities. (curricular-extra /extra-curricular)

22-When will the next ..flight be from London to New York?(Atlantic extra / transatlantic)

23-What they have to tell us may be intellectually shocking or emotionally..... ..(inacceptable/ unacceptable).

24-They worked like a. .machine.( oiled-well/well-oiled)

25-He had a mystical or experience.(religious-quasi/quasi-religious)

Q.2 Fill in the blanks with the appropriate forms of adjectival affixes (suffixes and prefixes) derived from the words between brackets. (25 marks)

1-Did he really see a ghost or was it only a Impression? (subject)

2-The money is to be used for a ... purpose. (specify)

3-The mother is about her son's health. (anxiety)

4-The prime minister made a appearance at the meeting. (person)

5-There was an story in the paper this morning. (amuse)

6-There is the danger of an explosion that could be caused by a gas leak. (accident)

7-The Time of my life was my childhood.

(happy)

8-He greeted them with a grin. (cheer)

9-Don't eat those berries. They're (poison)

10 -Her progress was slow in spite of her determination. (admire)

11-The convict was hiding in the loft.

(escape)

12-That was a very thing to do.( friend)

13-Many people believe that a dietrich in vitamin is very. (health)

14-The footpath was

(visible)

$15-\mathrm{He}$ is so ..... that you dare not criticize his work. (sensitive)

16-It was for him to drive

17-Machines are working with system. instructions. (regular) (matic)

18-He should not obey the

19-They were strange children. They behaved in an............way. (ordinary)

20-He found himself opposing Chamberlain in the .year.( war)

21-It is to play a transister in pubic places.

(social)

22-It is to sell cigarettes to children under 16 years.

(legal)

23-The child has a intelligence.

(normal)

24-She asked us to her house which was very small and (tidy)

25-He has reached an conclusion.

(logical) 